\title{
Soundscapes in aquaculture systems
}

\author{
Craig Radford ${ }^{1}$, Matthew Slater ${ }^{2, *}$ \\ ${ }^{1}$ Auckland University, Leigh Marine Laboratory, Institute of Marine Science, Auckland University, \\ PO Box 349 Warkworth 0941, New Zealand \\ ${ }^{2}$ Alfred-Wegener-Institute, Helmholtz Center for Polar and Marine Research, Am Handelshafen 12, 27570 Bremerhaven, \\ Germany
}

\begin{abstract}
Sound in aquaculture production systems remains poorly understood in terms of both biological effects and engineering possibilities. Open systems such as net pens and traditional ponds are increasingly being complemented by recirculating aquaculture systems (RAS). Each of these systems create soundscapes, which may have a significant effect on the high-value commercial species being farmed. The current study compared recordings of soundscapes from commercial net pens, earthen ponds, and concrete and high-density polyethylene RAS holding systems. Calibrated measurements of each acoustic habitat revealed the range and intensity of sound in each system type. Spectra of each type of holding system were overlaid with the hearing ranges and sensitivity levels of 4 commonly aquacultured fish, common carp Cyprinus carpio, European perch Perca fluviatilis, red sea bream Pagrus major and Atlantic salmon Salmo salar, and 1 crustacean, common prawn Palaemon serratus. The majority of ambient noise recorded in RAS systems and net pens fell within the 100 to $500 \mathrm{~Hz}$ range at or near fish hearing thresholds. While RAS systems are a markedly louder environment for species otherwise held in earthen ponds, the net pen environment clearly represents the most variable and loudest aquaculture holding system, reaching noise levels capable of eliciting a measurable physiological response in many species and revealing a likely source of chronic stress. The long-term stress response of culture animals and performance cost of inappropriate soundscapes remains undetermined. A precautionary approach and optimised system engineering is recommended to reduce the sound impact on culture animals to optimise growth performance.
\end{abstract}

KEY WORDS: Hearing thresholds $\cdot$ Noise $\cdot$ Stressor $\cdot$ Recirculating aquaculture systems $\cdot$ RAS Net pen · Pond

\section{INTRODUCTION}

Rapidly expanding aquaculture is an essential contributor to food security and economic growth worldwide; however, optimal animal welfare and ethical aquaculture methods are key to achieving sustainable production and maintaining consumer demand (Ashley 2007, FAO 2016). There are numerous stressors to animals held in captive aquaculture systems and, while their effects vary, if not managed correctly these typically lead to poor welfare and compromised fish health, ultimately affecting economic profitability and risking alternative purchase responses from high-end consumers (Olesen et al. 2010). Some stres-

\footnotetext{
${ }^{*}$ Corresponding author: matthew.james.slater@awi.de
}

sors associated with aquaculture may be unavoidable, and the fundamental goal for successful growth and production is the optimisation of strategies and practices to effectively manage or mitigate stress (Lucas \& Southgate 2012). One stressor of increasing interest in aquaculture is noise from biotic, and more importantly, abiotic and anthropogenic sources (Popper 2003). Hearing thresholds, where sound has been shown to elicit a physiological response, have been determined and reported for a large number of aquaculture-relevant species (Ladich \& Fay 2013). In previous physiological studies, high anthropogenic noise levels have been shown to alter fish behaviour (Sand et al. 2000, Zhou et al. 2016), decrease growth

() The authors 2019. Open Access under Creative Commons by Attribution Licence. Use, distribution and reproduction are unrestricted. Authors and original publication must be credited. 
(Filiciotto et al. 2013), damage hearing (McCauley et al. 2003) and increase stress responses (Wysocki et al. 2006), all of which may impact aquaculture production efficiency.

Potentially stressful soundscapes from production systems for commercially valuable aquaculture species remain, however, poorly investigated. There is a lack of information on aquaculture soundscapes and, in particular, a dearth of studies related to the variety of commercial production systems worldwide. Previous studies on noise and aquaculture species welfare in response to underwater sound are largely eco-physiological and relate to bentho-pelagic fish exposed to randomised anthropogenic noise in open seas and coastal areas (Filiciotto et al. 2013). Other preliminary studies of aquaculture species are limited to responses to extreme anthropogenic noise events, such as pile-driving and sounds exceeding $170 \mathrm{~dB}$ re $\mu \mathrm{Pa}$ (Edmonds et al. 2016, Zhou et al. 2016). Bart et al. (2001) showed that the sound produced in concrete tanks and ponds and fiberglass tanks are loudest in the low-frequency region (25 to $1000 \mathrm{~Hz}$ ) and within the hearing range of teleosts. Playbacks of soundscapes intended to simulate offshore (boat noise) and onshore (concrete tank) aquaculture environments have recently been shown to significantly affect oxidative status and immune/stress indicators in juvenile bream Sparus auratus (Filiciotto et al. 2017). Long-term exposure to inappropriate soundscapes, which can cause chronic stress in laboratoryheld rats Rattus norvegicus domesticus and compromise animal health and welfare in farmed pigs Sus scrofa domesticus, remain uninvestigated in aquaculture species (Van Raaij et al. 1996, Talling et al. 1998).

Aquaculture animals are exposed to a series and variety of system soundscapes throughout their production cycle. Pond and sea cage/net pen systems dominate finfish production worldwide (FAO 2016). Net pens are the primary method of production for salmonids and marine finfish; in excess of 5 million $t$ of Atlantic salmon Salmo salar are produced per year worldwide in temperate and sub-polar waters (FAO 2016). Also, large-scale European sea bass Dicentrarchus labrax and sea bream Sparus aurata net pen operations exist in the Mediterranean (Barazi-Yeroulanos, 2010). Earthen-lined and concrete pond systems in Asian nations are overwhelmingly the largest producers of finfish (FAO 2016). They are also pivotal in production of several species of shrimp and other high-value invertebrates worldwide with export markets of several million tonnes annually (FAO 2016). Recently, industry growth has been starkly impacted by space limitations and disease, while food safety and environmental concerns have impacted consumer acceptance (Ha et al. 2013). There is growing demand for ecologically sustainable, ethically produced high-end aquaculture products (FAO 2010, 2014). With increasing commercial pressure to efficiently use limited open aquaculture sites for ongrowing only, juvenile and early adult lifestage finfish are increasingly being held for longer periods in land-based recirculating aquaculture systems (RAS) (Joenson 2016). RAS systems are also increasingly important for the full production-cycle holding of high-value invertebrate species such as whiteleg shrimp Litopenaeus vannamei, as well as finfish, e.g. yellowtail kingfish Seriola lalandi. Each of these systems represent acoustic habitats worthy of more in-depth investigation in aquaculture research due to their potential link to possible behavioural or physiological effects on culture animals which may impact performance characteristics.

In the following study, passive acoustic recordings were made in 4 holding systems representing commercial aquaculture production worldwide: offshore net pens in New Zealand, onshore earthen ponds in Indonesia and onshore RAS systems constructed from concrete and high-density polyethylene (HDPE) in Germany. The soundscapes of each were compared with reported sound sensitivity thresholds for the most important aquaculture species available. Implications for production system choice and species limitations are reported.

\section{MATERIALS AND METHODS}

\subsection{Locations and production systems}

Passive acoustic recordings of underwater sound were performed in operating RAS, pond and net pen aquaculture systems. In all cases, except in ponds, continuous $24 \mathrm{~h}$ recordings were made using a ST300 hydrophone (Oceaninstruments; flat frequency response $20 \mathrm{~Hz}$ to $60 \mathrm{kHz}$ ) at $48 \mathrm{kHz}$, giving an upper analysable frequency limit of $24 \mathrm{kHz}$. All hydrophones were calibrated using a sound calibrator (G.R.A.S. Type 42AB) producing a $1 \mathrm{kHz}$ signal at $114 \mathrm{db}$ re $1 \mu \mathrm{Pa}$. In ponds, due to access and time constraints, only 3 representative ca. 2 min recordings were made from 3 ponds during normal operation. The pond recordings were made during daytime with fully operational paddlewheels at and directly after feeding. Paddlewheels run $24 \mathrm{~h} \mathrm{~d}^{-1}$ at the site, feeding is by hand 4 times daily. No aeration, pump- 
ing, physical intrusion or water disturbance is possible at the ponds.

RAS measurements were made at the Garnelen Farm Grevesmühlen, situated at Am Baarssee 5, 23936 Grevesmühlen, Germany, between 16 and 19 June 2017. The farm consists of twin RAS systems, located indoors, with a total volume of $200 \mathrm{~m}^{3}$. While RAS systems vary widely, particularly in terms of depth and tank size and make, the systems at Grevesmühlen are broadly representative of RAS systems used around the world in terms of sound sources. Each system consists of a moving-bed RAS biofiltration system, a solids removal drum filter connected to 2 large free-standing tanks each of ca. $80 \mathrm{~m}^{3}$ total volume and tank dimensions ca. $35 \times 5 \times 1 \mathrm{~m}$ (length $\times$ width $\times$ height) and filled to a water depth of ca. $0.7 \mathrm{~m}$. One system is made of ultra-high density cement slabs with a wall thickness of $50 \mathrm{~mm}$, the other system is made of HDPE plate with a thickness of $10 \mathrm{~mm}$. Whiteleg shrimp Litopenaeus vannamei are held at densities of up to $3.5 \mathrm{~kg} \mathrm{~m}^{-3}$ or ca. 150 animals $\mathrm{m}^{-2}$ within the tanks. In addition to standard filtration components, potential sound sources in the RAS systems include water pumps, air injection systems and reverse flushing spray units on the drum filters. Hydrophones were hung midwater $(0.4 \mathrm{~m}$ depth and $0.3 \mathrm{~m}$ to the nearest surface) centrally in tanks at 3 points equidistant from tank walls but at increasing distance along the tank length from the water processing system/pump house.

Recordings in pond systems were made at a small commercial whiteleg shrimp $L$. vannamei facility in Kraksaan, Probolinggo/Malang, East Java, Indonesia, on 20 November 2017. The farm consists of 5 polyethylene film-lined earthen ponds of ca. $2000 \mathrm{~m}^{2}$ connected by single supply and drainage channels to an estuarine water supply. Pond dimensions are ca. $40 \times 50 \times 3 \mathrm{~m}$ (length $\times$ width $\times$ height) and are filled to a water depth of ca. $1.5 \mathrm{~m}$. Ponds were initially stocked with ca. 250 shrimp $\mathrm{m}^{-2}$. Potential sound sources in the pond systems are limited to surface aeration units (paddlewheels) only. Hydrophones were hung midwater $(0.5 \mathrm{~m}$ depth and $0.75-1.0 \mathrm{~m}$ to the nearest surface) in ponds at 3 points (from access walkways above the ponds) equidistant from pond walls and from paddlewheels.

Recordings were made at 3 points $(1$ in the centre of the farm and 2 at farm edges) at the NZ King Salmon Farm at Ruakaka Bay, Marlborough Sounds, New Zealand, between 6 and 11 December 2016. Recordings were also made at 3 reference sites to compare the sound generated by the farm to ambient/background marine sound. The farm consists of
12 net pens with a surface area of 225 to $250 \mathrm{~m}^{2}$ and a depth of $15 \mathrm{~m}$ mounted on a floating barge and floating HDPE walkway system. Net pens were stocked with varying densities and sizes of Chinook salmon Oncorhynchus tshawytscha. In addition to the floating structures and the stocked fish, potential sound sources included access vessels, an associated feed barge, oxygen storage, compressed air automated feeders and a temporary handling facility linked to the site. Hydrophones were hung at 3 points to a depth of ca. $2.5 \mathrm{~m}$ at the pen edge $(1 \mathrm{~m}$ to the nearest surface), within a net pen and from an access walkway ca. $1 \mathrm{~m}$ beyond the pen edge. Recordings at reference sites were made at $2.5 \mathrm{~m}$ depth. Reference sites were a navigation buoy (nav. buoy) within the shipping lane of an associated sound (representative of a highly anthropogenically impacted soundscape), a jetty mooring (jetty) in a quiet bay $1.2 \mathrm{~km}$ from the farm and a mooring buoy (mooring) ca. $2 \mathrm{~km}$ from the farm (representative of background noise levels).

\subsection{Sound processing and analysis}

For net pen and RAS data, RMS levels of the power spectral density (PSD), 1st, 5th, 50th, 95th and 99th percentiles and spectra probability density (SPD) were calculated for each tank position as $5 \mathrm{~min}$ averages of the $24 \mathrm{~h}$ recording. The percentage of recordings with boat noise in them was determined on these 5 min averages. To compare the ponds from Indonesia to those of the RAS systems from Germany and net pens from New Zealand, RMS levels of the PSD were plotted. All sound spectral analyses were carried out in MATLAB using scripts adapted from PAMGuide (Merchant et al. 2015). These spectra were visually assessed to examine general trends in acoustic behaviour. In order to determine the actual impact on key aquaculture species, both physiological and behaviourally determined hearing threshold data from the literature was manually overlaid onto PSD plots of soundscapes in each aquaculture system. Key species selected were common carp Cyprinus carpio, Atlantic salmon Salmo salar, European perch Perca fluviatilis, red sea bream Pagrus major and common prawn Palaemon serratus.

\section{RESULTS}

Overall, sound levels were consistently higher at the net pen farm, ranging from 107 to $112 \mathrm{~dB}$ re $1 \mu \mathrm{Pa}$, depending on hydrophone position within the farm. 
These levels were higher compared to 2 of the control sites, jetty and mooring, which ranged from 98 to $99 \mathrm{~dB}$ re $1 \mu \mathrm{Pa}$ (Table 1 ). The location of the hydrophone in the RAS system affected overall sound levels: closer to the pump house was louder than the opposite end of the tank. Type of tank also affected the sound levels, with HDPE being on average slightly quieter than concrete tanks (Table 2). The quietest system was the earthen pond (Table 2).

PSD levels at the nav. buoy associated with a shipping channel (Fig. 1F) site were similar to all locations at the salmon farm site. All sites exhibited a large amount of variability in PSD levels, with differences between the 1st and 99th percentiles ranging from 20 to $60 \mathrm{~dB}$. The inside net pen farm site (Fig. 1C) had an unusual notch in the PSD between 200 and $700 \mathrm{~Hz}$ which was not observed at any of the other recording sites. Both the outside net pen farm sites (Fig. 1A,B) had higher PSD levels between 20 and $1000 \mathrm{~Hz}$ compared to the mooring and jetty sites, which only had increased low-frequency PSD levels between 30 and $100 \mathrm{~Hz}$. Above $1000 \mathrm{~Hz}$, the net pen farm sites were also louder than all control sites.

The only notable differences between the 2 RAS systems was that the concrete tanks were louder on average and that position in relation to the pump house influenced the recorded sound levels. Below $1000 \mathrm{~Hz}$, there was $<1.5 \mathrm{~dB}$ difference between the 1st and 99th percentiles, indicating there was little variation in PSD in both the indoor tank types and hydrophone position in relation to the pump house. However, above $1000 \mathrm{~Hz}$, there was large variation between 5 and $20 \mathrm{~dB}$ between the 1st and 99th percentiles (Fig. 2). On average, the variability of measured sound in net pen systems was much greater than in the indoor RAS systems.

The short-term analysis of the earthen pond recordings showed that sound levels were markedly lower compared to the indoor RAS system and the outdoor net pen farm (Fig. 3). In the frequency band 30 to $300 \mathrm{~Hz}$, the outdoor pond system was on the order of 10 to $30 \mathrm{~dB}$ quieter than both indoor RAS systems and the outdoor net pen system (Fig. 3).

Both the indoor RAS systems and the outdoor net pen farm
Table 2. Sound levels ( $\mathrm{dB}$ re $1 \mu \mathrm{Pa}$ ) at the recirculating aquaculture system (RAS) site in Grevesmühlen, Germany, and the pond aquaculture site in East Java, Indonesia. RMS; root mean square $\pm \mathrm{SE}_{;} 95 \%$ : 95th percentile; $5 \%$ : 5 th percentile; HDPE: high-density polyethylene

\begin{tabular}{|c|c|c|c|c|c|c|c|}
\hline & \multicolumn{3}{|c|}{ Concrete- } & \multicolumn{3}{|c|}{$\longrightarrow$ HDPE - } & \multirow{2}{*}{$\begin{array}{c}\text { Earthen } \\
\text { pond }\end{array}$} \\
\hline & $\begin{array}{l}\text { Closest } \\
\text { pump } \\
\text { house }\end{array}$ & Mid-tank & $\begin{array}{c}\text { Farthest } \\
\text { pump } \\
\text { house }\end{array}$ & $\begin{array}{l}\text { Closest } \\
\text { pump } \\
\text { house }\end{array}$ & Mid-tank & $\begin{array}{c}\text { Farthest } \\
\text { pump } \\
\text { house }\end{array}$ & \\
\hline RMS & $103 \pm 1$ & $100 \pm 1$ & $96 \pm 1$ & $102 \pm 1$ & $98 \pm 1$ & $96 \pm 1$ & $75 \pm 1$ \\
\hline Median & 103 & 101 & 96 & 102 & 99 & 95 & \\
\hline $95 \%$ & 106 & 102 & 98 & 103 & 99 & 97 & \\
\hline $5 \%$ & 102 & 100 & 94 & 100 & 97 & 94 & \\
\hline
\end{tabular}



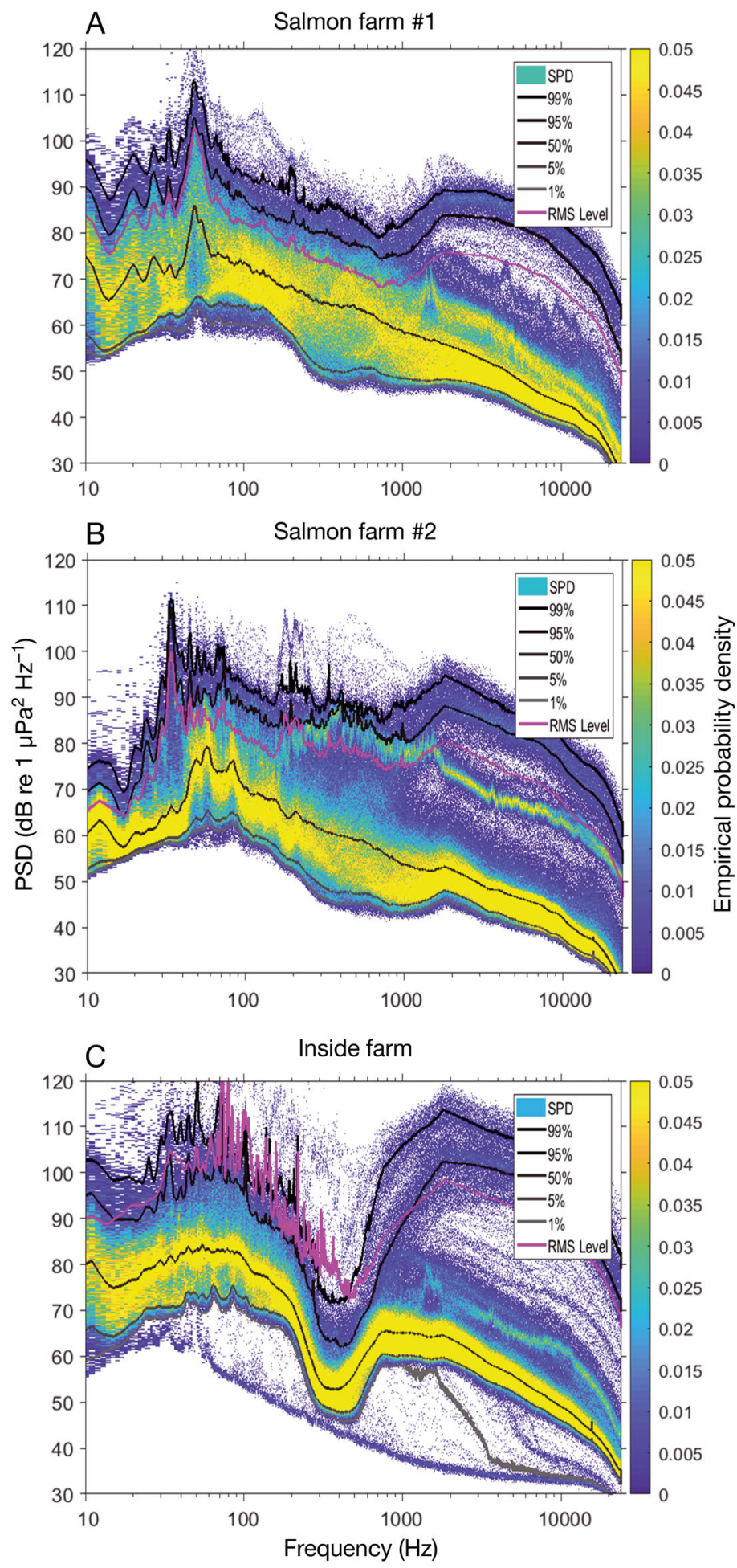
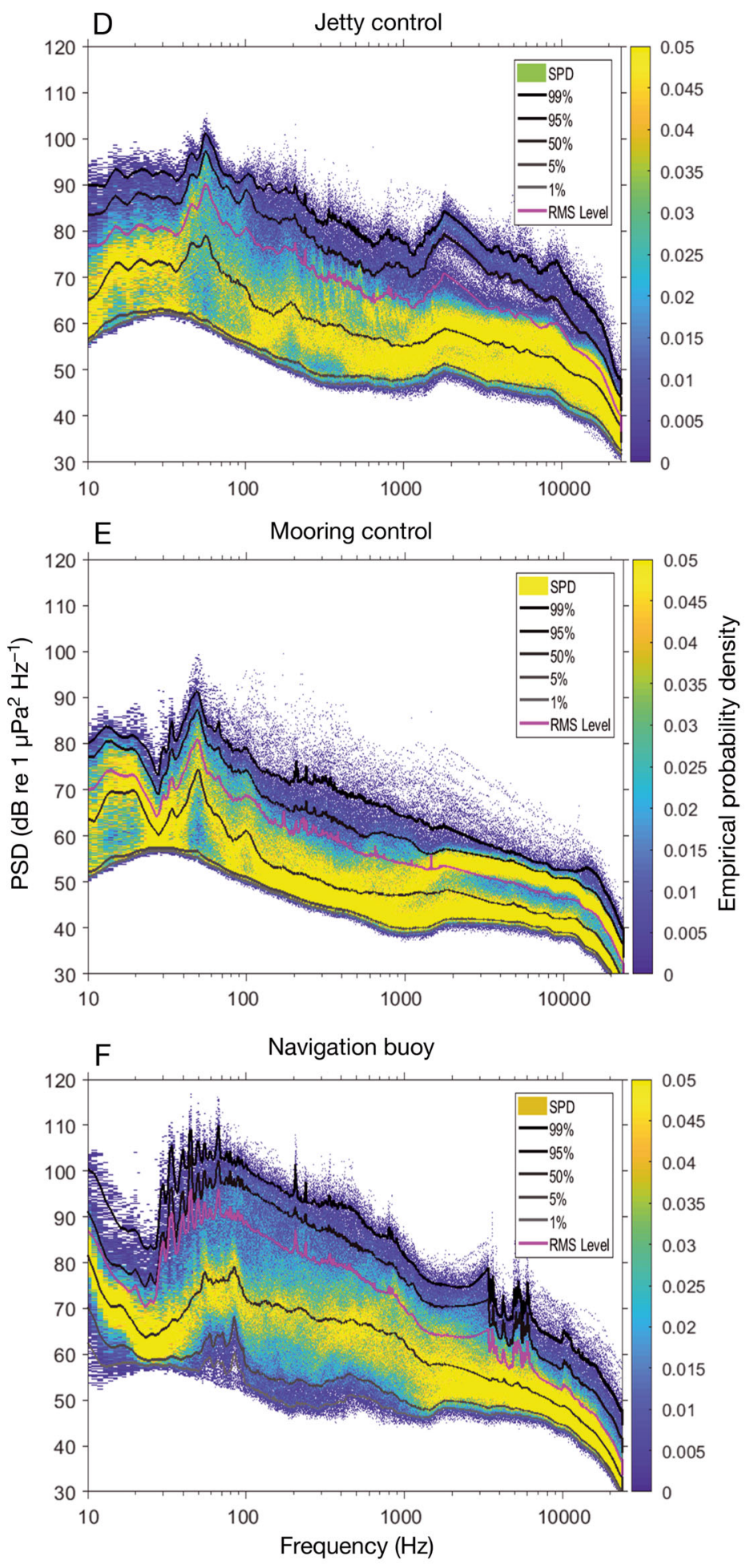

Fig. 1. Statistical analysis (RMS level of the power spectral density [PSD], percentiles [1, 5, 50, 95, 99\%] and statistical probability density [SPD]) of the $24 \mathrm{~h}$ recordings from 3 sites at $(A, B, C)$ the net pen salmon farm and $(D, E, F) 3$ control sites away from the net pen salmon farm. Sampling rate $48 \mathrm{kHz}, 24$ bit. The 3 farm sites and the navigation buoy exhibit significant boat noise below $1000 \mathrm{~Hz}$ compared to the jetty and mooring control sites 
Plastic tanks
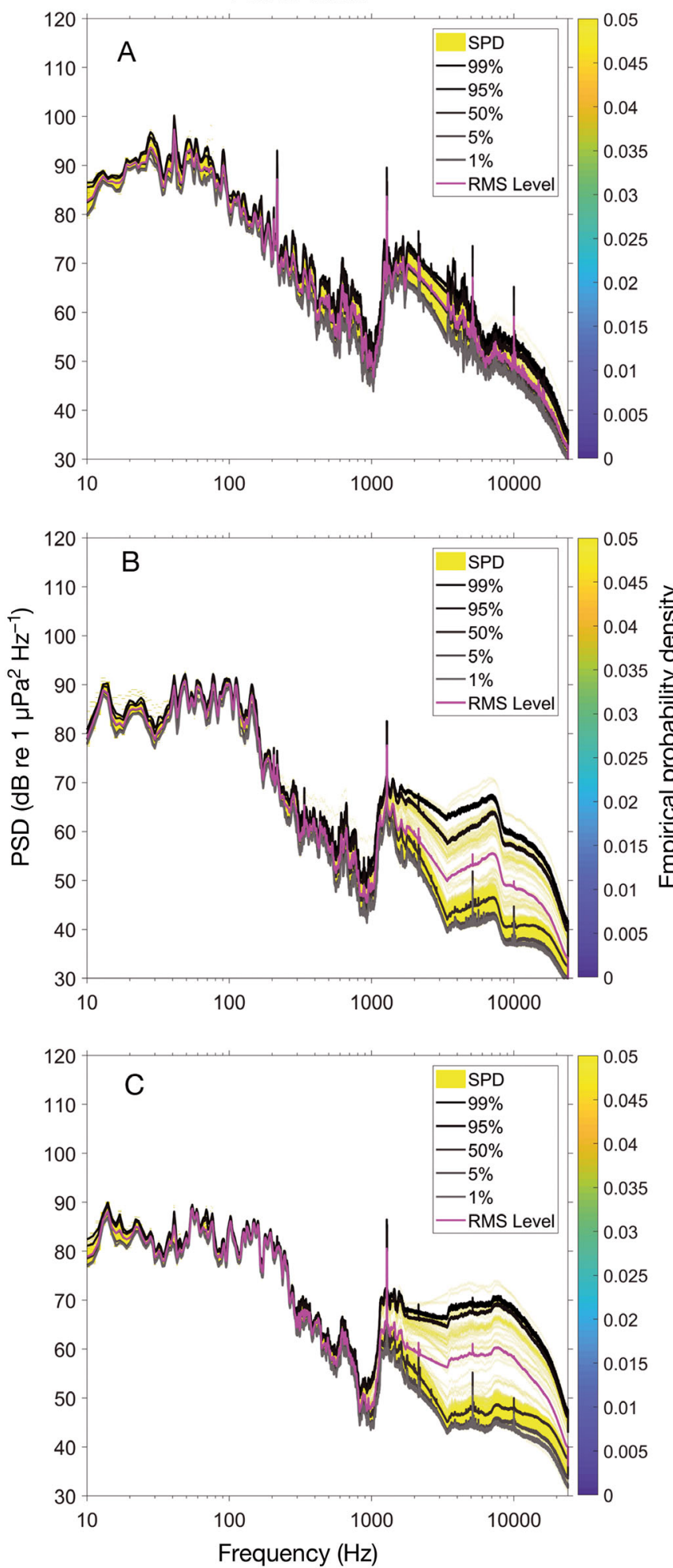

\section{Concrete tanks}
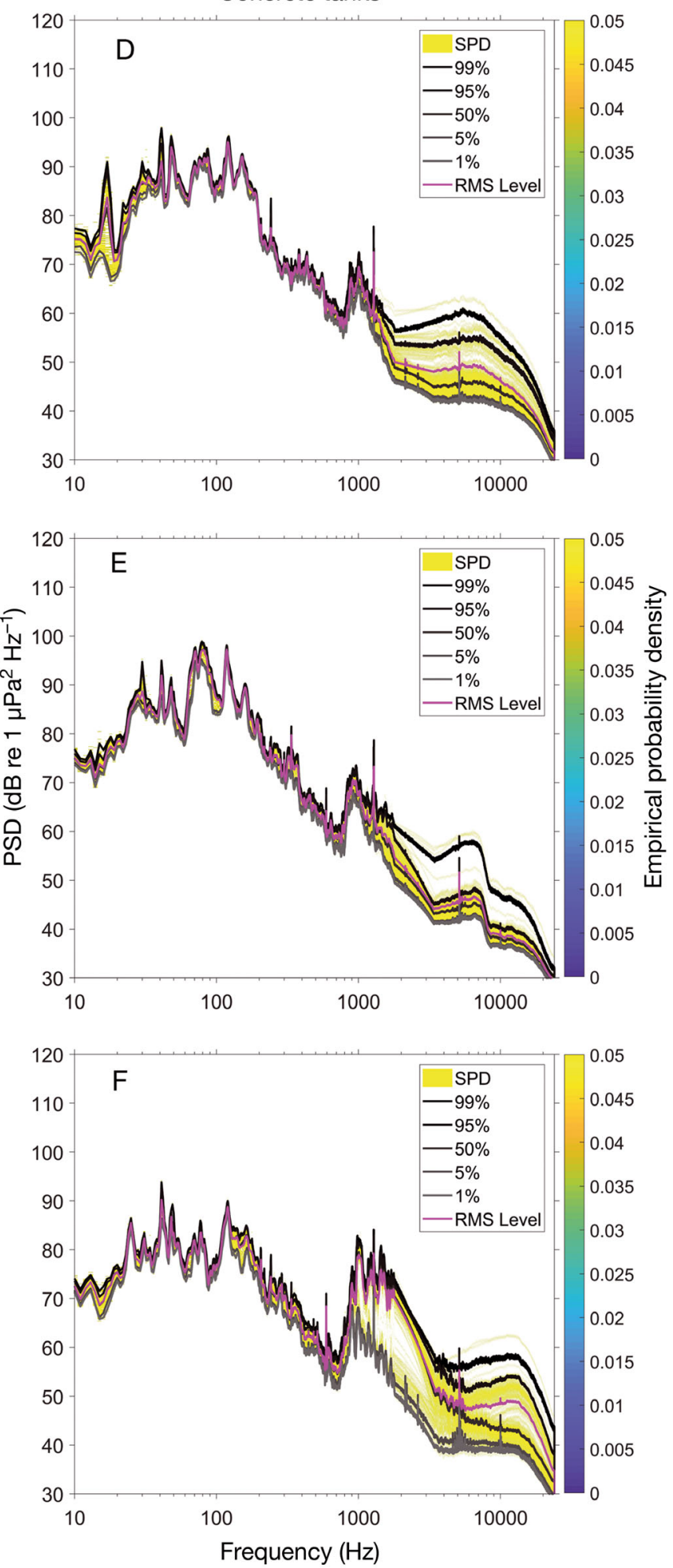

Fig. 2. Statistical analysis (RMS level of the power spectral density [PSD], percentiles [1, 5, 50, 95, 99\%] and statistical probability density [SPD]) of the $24 \mathrm{~h}$ recordings from each tank type and position related to the pump house. (A) Plastic (HDPE) furthest from pump house; (B) plastic (HDPE) middle; (C) plastic (HDPE) closest to pump house; (D) concrete furthest from pump house; (E) concrete middle; (F) concrete closest to pump house. Sampling rate $48 \mathrm{kHz}, 24$ bit. The plastic tanks were on average quieter than the concrete tanks and the end of the tank furthest from the pump house was also the quietest location within 


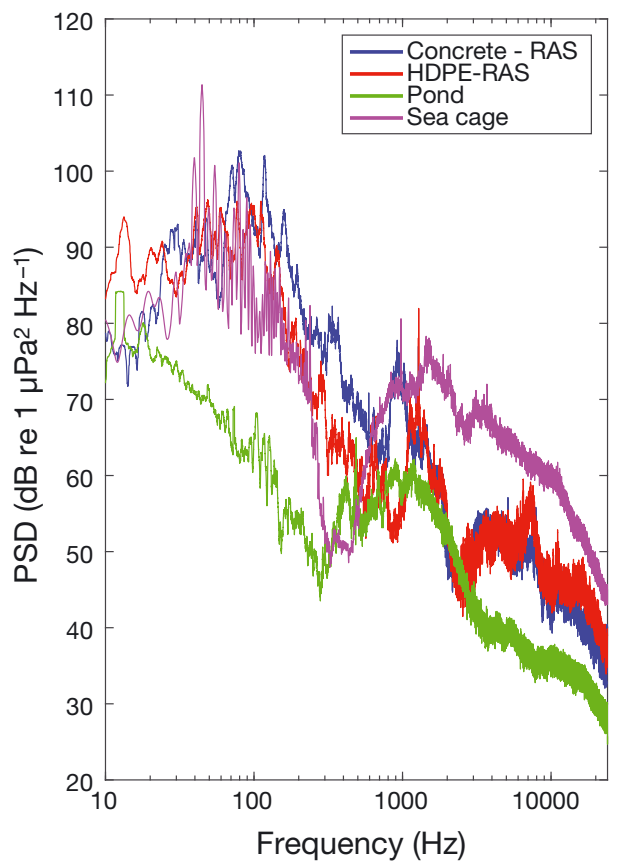

Fig. 3. PSD plot comparing the middle of the concrete and HDPE indoor RAS culture tanks, outdoor salmon farm and outdoor earthen pond culture systems. Sampling rate $48 \mathrm{kHz}, 24$ bit. Below $1000 \mathrm{~Hz}$ the outdoor net pen and RAS systems had comparable sound levels, whereas the earthen pond systems were quieter

etest. Furthermore, the majority of the sound produced or associated with all aquaculture production systems was greatest at low frequencies $(<1000 \mathrm{~Hz})$, which is within the hearing range of fish and crustaceans, in particular aquaculture candidate species. The sound conditions that aquaculture species are exposed to have the potential to cause chronic stress and affect performance, health status and immune responses, and thus need to be understood in a differentiated manner (Filiciotto et al. 2016, 2017).

The level of variability exhibited by the net pen culture system compared to all other production systems analysed can be attributed to the openness of the system, the site and the extraneous sources of
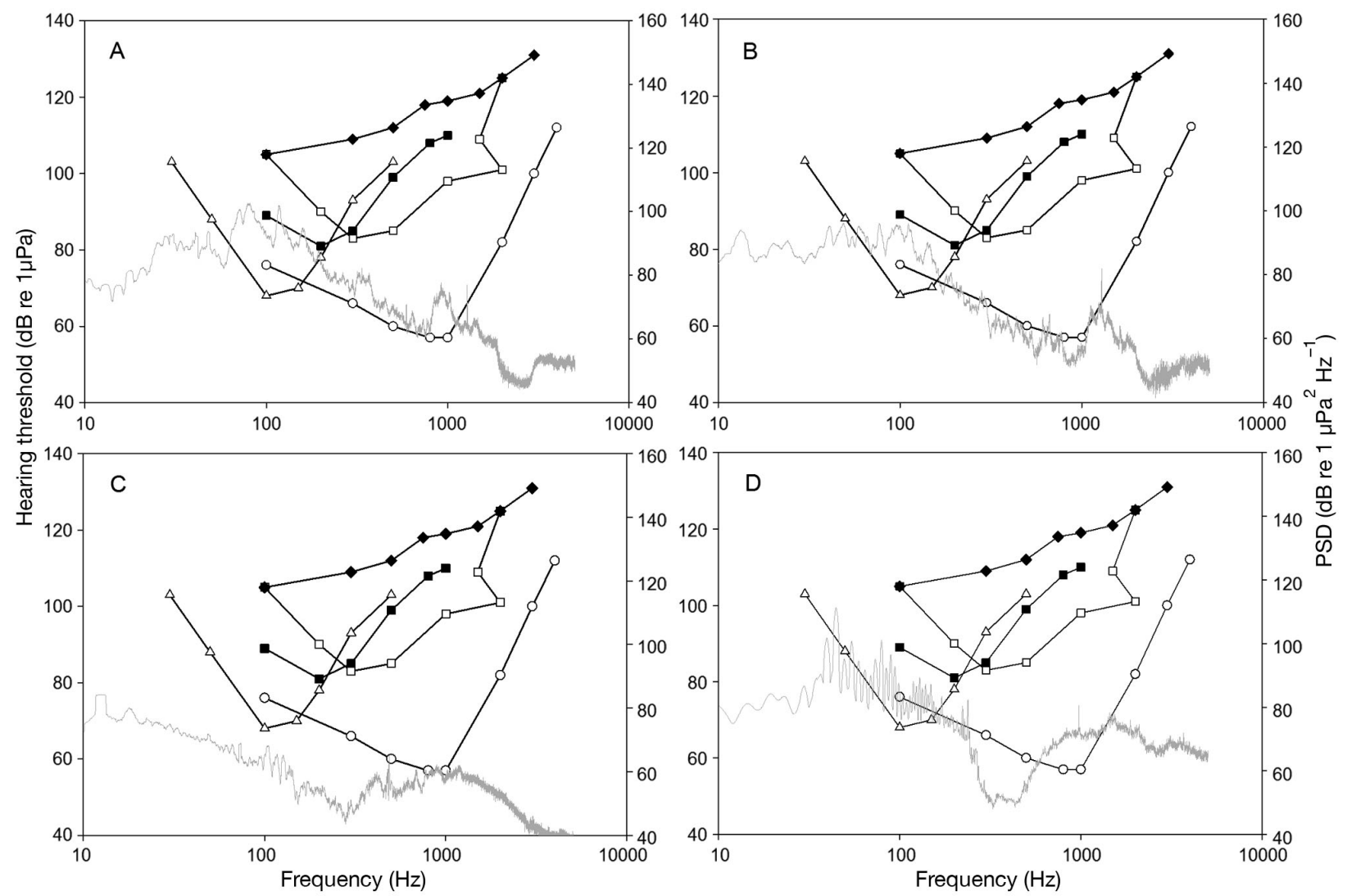

Fig. 4. Physiologically determined hearing thresholds of 5 representative aquaculture species overlaid on the PSD analysis (light grey line) of the 4 aquaculture production system types: (A) RAS concrete tanks; (B) RAS HDPE tanks; (C) land-based earthen pond system; (D) outdoor net pen system. Open circle: common carp Cyprinus carpio (Amoser \& Ladich 2005); open triangle: Atlantic salmon Salmo salar (Hawkins \& Johnstone 1978); closed square: European perch Perca fluviatilis (Amoser \& Ladich 2005); open square: red sea bream Pagrus major (Kojima et al. 2010); closed diamond: common prawn Palaemon serratus (Lovell et al. 2005). Atlantic salmon, European perch and common carp would be the only fish that could potentially detect the noise from RAS or outdoor net pen aquaculture, whereas only the common carp could potentially detect earthen pond culture noise 

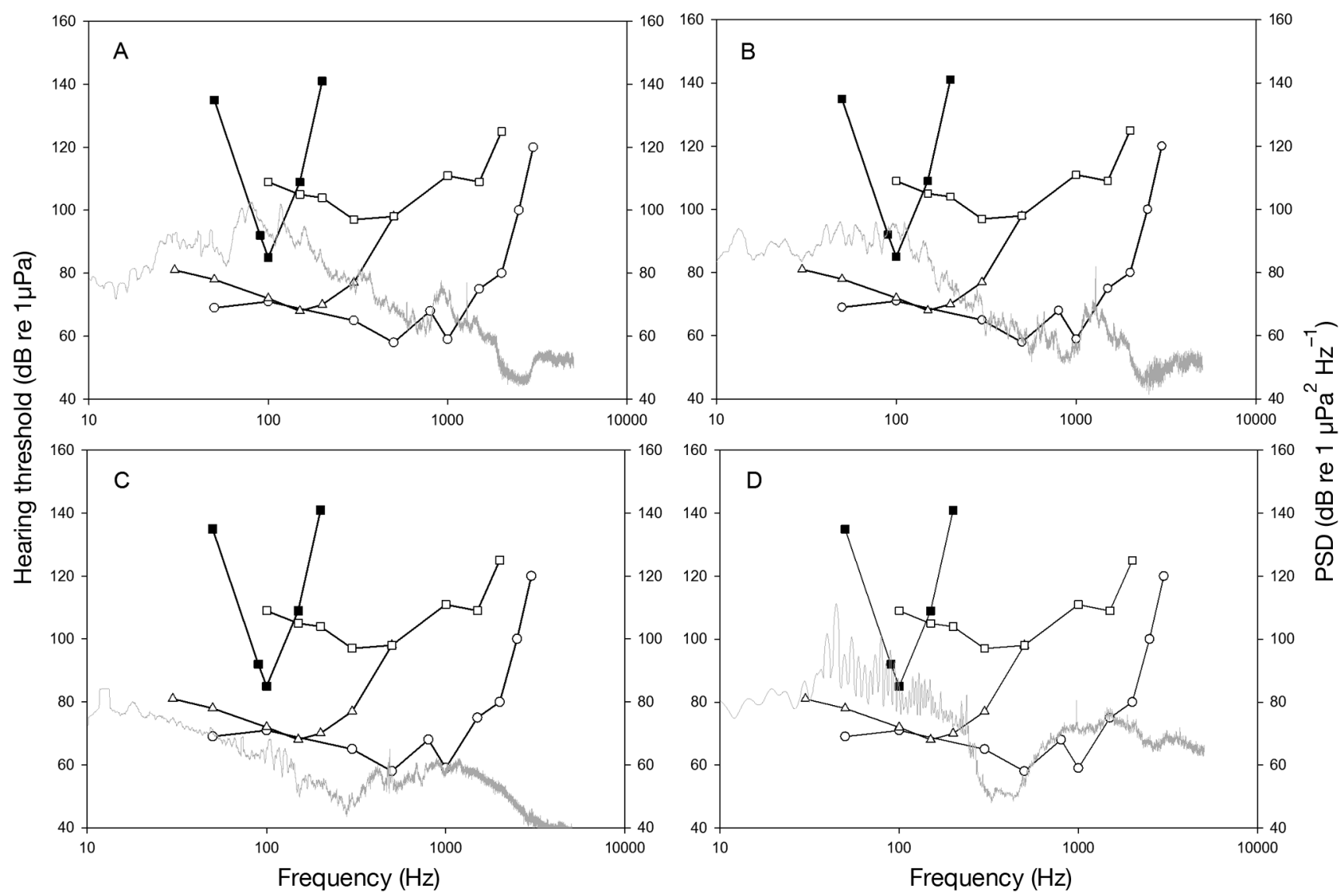

Fig. 5. Behaviourally determined hearing thresholds of 4 representative aquaculture species overlaid on PSD analysis (light grey line) of the 4 aquaculture production system types: (A) RAS concrete tanks; (B) RAS HDPE tanks; (C) land-based earthen pond system; (D) outdoor net pen system. Open circle: common carp Cyprinus carpio (Popper 1972); open triangle: Atlantic salmon Salmo salar (Hawkins \& Johnstone 1978); closed square: European perch Perca fluviatilis (Wolff 1967); open square: red sea bream Pagrus major (Kojima et al. 2010). European perch, common carp and Atlantic salmon could potentially detect the noise from the RAS and outdoor net pen systems, whereby Atlantic salmon and common carp could potentially detect the noise from the earthen pond system

sound from the environment, as much as the aquaculture production system itself. The sources of these sounds can be abiotic, biotic or anthropogenic. Abiotic or physical sources include wind, rain and water turbulence, biotic sources are those produced by living organisms, and anthropogenic sources are manmade sources, such as boat sounds or oxygen injectors and pumps. The recordings were conducted under ideal weather conditions, with little wind and no rain, therefore abiotic sources are not likely to have been responsible for the observed variation. A range of sound-producing animals can be found in the farm vicinity, including bluefin gurnard Chelidonichthys kumu and snapping shrimp Alphaeus sp. (Radford et al. 2016). It is unlikely that the bluefin gurnard are present in sufficient numbers to cause the variability observed in the low frequencies $(<1000 \mathrm{~Hz})$; however, it is highly likely that the density of snapping shrimp is large enough to be responsible for the variability at higher frequencies. Due to a constant source of uneaten salmon feed and faeces, the shrimp are likely to be present in greater numbers under the farm, which potentially explains the difference between the control and farm sites in this frequency band

Anthropogenic noise in the form of boats servicing the salmon farm, recreational craft or distant commercial activity drives the variability observed in the low frequencies $(<1000 \mathrm{~Hz})$. Boat noise, from either commercial or recreation sources, has been shown to influence fish in numerous ways, from behavioural effects to physiological damage (Sand et al. 2000, McCauley et al. 2003, Wysocki et al. 2006, Filiciotto et al. 2016, Zhou et al. 2016). Fish at high density, as is generally the case in aquaculture, potentially already encounter a number of external stressors. Boat noise contributing to an unsuitable soundscape has the potential to add further stress to cultured animals. 
While biotic and many abiotic sounds are difficult or impossible to control, limiting access of recreational or otherwise non-essential motorboats to near-farm sites may be a first step in reducing sound stress at net pen sites.

If in open systems, biotic and external anthropogenic sounds present external challenges in terms of mitigation and control, in RAS systems, challenges are almost entirely related to system design. The engineering considerations for RAS are manifold and include cost and operational practicality, among others. However, if it is apparent or possible that the acoustic habitat will affect the culture species performance in terms of growth (especially sensitive juvenile life stages), then sound, particularly in hightech systems such as RAS, will become an additional aspect to consider in aquaculture engineering. Proximity to pumping and biofiltration increases loudness, thus simple distancing of holding tanks from water treatment is recommendable. In addition, quieter pumps and water flows (low surface impact) can reduce system sound. Aeration/oxygen injection produces significant noise as bubbles collapse; however, the production of microbubbles can increase frequencies to beyond hearing thresholds. Alternatively, oxygenation can be carried out in cone systems separate (and distant) from holding tanks.

While sound in varying aquaculture production systems is clearly within the behaviourally and physiologically determined hearing ranges of key species, the effects of inappropriate soundscapes may also differ strongly between culture species, not only as a result of physiological ability to perceive sound, but also of their behaviour. Shrimp or flatfish species, for example, primarily remain on the floor, walls and other surfaces within RAS tanks and may thus be exposed to different soundscapes and greater transmission from the vibrations in/on the tank itself compared to pelagic fish (Roberts \& Elliott 2017). In modern commercial aquaculture, particularly in the case of finfish, it is highly likely that an animal will experience several of the studied production systems in its life cycle (Joenson 2016). It remains undetermined how key aquaculture species adapt to abrupt changes in perceived ambient sound and whether, for example, a juvenile finfish bred in RAS experiences an additional adaptation stressor when moved to net pens due to the altered soundscape. It is also important to note that sensory structures may change and hence function differently in aquacultured animals. For example, Reimer et al. (2017) showed that in Atlantic salmon Salmo salar, the mineral composition of the otoliths (hearing structures) change from arag- onite to vateritic, which causes a possible 28 to $50 \%$ decrease in normal function. Hearing the sound does not directly imply the sound will induce stress. A multitude of factors, such as sound intensity, exposure duration and animal behaviour, all contribute to whether the sound will cause stress in the species in question (Slabbekoorn et al. 2010).

To the authors' knowledge there has only been one other study investigating the sound levels in aquaculture systems. Bart et al. (2001) reported sound levels produced by an indoor raceway system and an outdoor earthen pond, which were similar to both the RAS and earthen pond systems recorded in the present study. As with the current study, the raceway system was louder than the earthen pond system recordings. Fibreglass tanks were found to be louder than concrete-based raceway tanks (Bart et al. 2001). Here, concrete tanks were compared to HDPE tanks, and the HDPE tanks were 2 to $3 \mathrm{~dB}$ quieter. Recording location within the tank is also critical. Like Bart et al. (2001), we found that recording location, in particular proximity to the pumps, resulted in different sound conditions. This makes sense because the acoustics of tanks is very complex, due to the constrained sound propagation conditions (Parvulescu 1967).

In conclusion, net pen systems were the loudest aquaculture production system examined, most likely because of the effect of boat noise due to service vessels or other transiting boats. All net pen cultured fish (with the exception of Atlantic bluefin tuna Thunnus thynnus), including salmon, sea bass and sea bream, are grown out in net pens following breeding in land-based tanks and RAS systems. These animals may be under a considerable amount of stress from a variety of inappropriate soundscapes, potentially affecting animal health and growth rates. RAS systems are comparatively loud and might cause stress in more sensitive species or early life stages. However, through innovative engineering, such as technology to reduce or distance pump and bubble noise from holding tanks, RAS has the potential to be much quieter. Earthen ponds are examples of best practice in terms of reducing the stress induced by noise and represent a target noise level for novel production systems to aim for. Many questions remain open in terms of aquaculture soundscapes and the species exposed to them. The role of acclimation and adaptation amongst culture species is unresearched, as is the potential for 'positive sounds' in systems. Future studies are further necessary to determine the impact of chronic sound exposure in key aquaculture species. 
Acknowledgements. The authors wish to express their thanks to Mr Karl Bissa and Mr York Dyckerhof of Green Aqua Farming / Cara Royale in Germany, Mr Surya Liauw and Mr. Stephan Neumayer of Evonik (Indonesia/Active Oxygens) and Mr Mark Preece of New Zealand King Salmon for access and logistical support.

\section{LITERATURE CITED}

Amoser S, Ladich F (2005) Are hearing sensitivities of freshwater fish adapted to the ambient noise in their habitats? J Exp Biol 208:3533-3542

Ashley PJ (2007) Fish welfare: current issues in aquaculture. Appl Anim Behav Sci 104:199-235

Barazi-Yeroulanos L (2010) Aquaculture in the Mediterranean. https://thefishsite.com/articles/aquaculture-inthe-mediterranean

Bart AN, Clark J, Young J, Zohar Y (2001) Underwater ambient noise measurements in aquaculture systems: a survey. Aquacult Eng 25:99-110

Edmonds NJ, Firmin CJ, Goldsmith D, Faulkner RC, Wood DT (2016) A review of crustacean sensitivity to high amplitude underwater noise: data needs for effective risk assessment in relation to UK commercial species. Mar Pollut Bull 108:5-11

FAO (2010) Shrimp - February 2010. Food and Agriculture Organization, Rome. www.fao.org/in-action/globefish/ market-reports/resource-detail/en/c/338096/

FAO (2014) Fisheries Global Information System. Food and Agriculture Organization. www.fao.org/fishery/figis/en

FAO (2016) The State of World Fisheries and Aquaculture 2016 (SOFIA): Contributing to food security and nutrition for all. Food and Agriculture Organization, Rome

Filiciotto F, Giacalone VM, Fazio F, Buffa G and others (2013) Effect of acoustic environment on gilthead sea bream (Sparus aurata): sea and onshore aquaculture background noise. Aquaculture 414-415:36-45

Filiciotto F, Vazzana M, Celi M, Maccarrone V and others (2016) Underwater noise from boats: measurement of its influence on the behaviour and biochemistry of the common prawn (Palaemon serratus, Pennant 1777). J Exp Mar Biol Ecol 478:24-33

Filiciotto F, Cecchini S, Buscaino G, Maccarrone V, Piccione G, Fazio F (2017) Impact of aquatic acoustic noise on oxidative status and some immune parameters in gilthead sea bream Sparus aurata (Linnaeus, 1758) juveniles. Aquacult Res 48:1895-1903

* Ha TTP, van Dijk H, Bosma R, Sinh LX (2013) Livelihood capabilities and pathways of shrimp farmers in the Mekong Delta, Vietnam. Aquac Econ Manag 17:1-30

Hawkins AD, Johnstone ADF (1978) The hearing of the Atlantic salmon, Salmo salar. J Fish Biol 13:655-673

Joenson R (2016). Large smolts in salmon farming. Sjávarútvegsráðstefnan 2016, Hörpu, Rekjavik

Kojima T, Suga T, Kusano A, Shimizu S and others (2010) Acoustic pressure sensitivities and effects of particle motion in red sea bream Pagrus major. Fish Sci 76:13-20

Editorial responsibility: Tim Dempster,

Melbourne, Victoria, Australia
Ladich F, Fay RR (2013) Auditory evoked potential audiometry in fish. Rev Fish Biol Fish 23:317-364

*Lovell JM, Findlay MM, Moate RM, Yan HY (2005) The hearing abilities of the prawn Palaemon serratus. Comp Biochem Physiol A 140:89-100

Lucas J, Southgate P (2012) Aquaculture: farming aquatic animals and plants. Wiley-Blackwell, Chichester

McCauley RD, Fewtrell J, Popper AN (2003) High intensity anthropogenic sound damages fish ears. J Acoust Soc Am 113:638-642

Merchant ND, Fristrup KM, Johnson MP, Tyack PL, Witt MJ, Blondel P, Parks SE (2015) Measuring acoustic habitats. Methods Ecol Evol 6:257-265

Olesen I, Alfnes F, Røra MB, Kolstad K (2010) Eliciting consumers' willingness to pay for organic and welfarelabelled salmon in a non-hypothetical choice experiment. Livest Sci 127:218-226

Parvulescu A (1967) The acoustics of small tanks. In: Tavolga WN (ed) Marine bioacoustics, Vol 2. Pergamon, Oxford, p 7-13

Popper AN (1972) Pure-tone auditory thresholds for the carp, Cyprinus carpio. J Acoust Soc Am 52:1714-1717

* Popper AN (2003) Effects of anthropogenic sounds on fishes. Fisheries (Bethesda, Md) 28:24-31

* Radford CA, Ghazali SM, Montgomery JC, Jeffs AG (2016) Vocalisation repertoire of female bluefin gurnard (Chelidonichthys kumu) in captivity: sound structure, context and vocal activity. PLOS ONE 11:e0149338

Reimer T, Dempster T, Wangelius A, Fjelldal PG and others (2017) Rapid growth causes abnormal vaterite formation in farmed fish otoliths. J Exp Mar Biol 220:2965-2969

Koberts L, Elliott M (2017) Good or bad vibrations? Impacts of anthropogenic vibration on the marine epibenthos. Sci Total Environ 595:255-268

* Sand O, Enger PS, Karlsen HE, Knudsen F, Kvernstuen T (2000) Avoidance responses to infrasound in downstream migrating European silver eels, Anguilla anguilla. Environ Biol Fishes 57:327-336

* Slabbekoorn H, Bouton N, van Opzeeland I, Coers A, ten Cate C, Popper AN (2010) A noisy spring: the impact of globally rising underwater sound levels on fish. Trends Ecol Evol 25:419-427

Talling JC, Lines JA, Wathes CM, Waran NK (1998) The acoustic environment of the domestic pig. J Agric Eng Res 71: $1-12$

V Van Raaij MTM, Oortgiesen M, Timmerman HH, Dobbe CJG, Van Loveren H (1996) Time-dependent differential changes of immune function in rats exposed to chronic intermittent noise. Physiol Behav 60:1527-1533

Wolff DL (1967) Das Hoervermoegen des Flußbarsches (Perca fluviatilis L.). Biol Zentralbl 86:449-460

Wysocki LE and others (2006) Ship noise and cortisol secretion in European freshwater fishes. Biol Conserv 128:501-508

Zhou WZR, Xu X, Tu X, Chen Y (2016) Preliminary exploration for effects of sound stimulus on the movement behavior of Litopenaeus vannamei. 2016 IEEE/OES China Ocean Acoustics Symposium (COA), 9 to 11 January 2016, Harbin

Submitted: September 3, 2018; Accepted: November 19, 2018 Proofs received from author(s): February 8, 2019 